\title{
PEMANFAATAN TEKNOLOGI PANEL SURYA KELOMPOK PETANI BUNGA KRISAN DI DESA BLARANG DAN DESA GENDRO KECAMATAN TUTUR KABUPATEN PASURUAN
}

\author{
Lauhil Mahfudz Hayusman ${ }^{1 *}$, Asroful Anam², Taufik Hidayat ${ }^{3}$ \\ 1,2,3Fakultas Teknologi Industri, Institut Teknologi Nasional Malang \\ *Email Korespondensi: hayusman@1ecturer.itn.ac.id
}

\begin{abstract}
ABSTRAK
Kelompok Petani Patmasari I Desa Blarang dan Kelompok Petani Sekar Sari Desa Gendro, Kecamatan Tutur, Kabupaten Pasuruan, merupakan kelompok tani yang bergerak dibidang budidaya bunga krisan. Varietas bunga krisan yang dihasilkan beraneka ragam, dan dikirim untuk memenuhi permintaan pasar lokal yaitu Malang dan Surabaya. Harga jual bunga krisan dipengaruhi oleh kualitas atau mutu bunga. Kasus dilapangan menunjukan bahwa bunga krisan hasil budidaya para petani masih kurang baik, salah satu penyebabnya yaitu proses pencahayaan tambahan tanaman krisan di malam hari yang kurang maksimal masih mengandalkan sumber energi listrik dari PLN. Pada saat-saat tertentu sering terjadi pemadaman listrik terlebih pada saat musim hujan. Disamping itu, instalasi listrik green house yang dimiliki petani masih belum standar, hal ini secara langsung akan berdampak pada keamanan dan kualitas hasil produksi bunga krisan. Hasil kegiatan yang sudah dilakukan yaitu perakitan dan pemasangan masing-masing PLTS kapasitas 1.200 Watt yang digunakan untuk suplai daya listrik pencahayaan tanaman krisan pada Mitra-1dan proses irigasi pada Mitra-2. Melakukan revitalisasi instalasi listrik green house indukan dan green house pembibitan. Selain itu juga dilakukan penyuluhan tentang pemanfaatan sumber energi alternatif yang ramah lingkungan dan instalasi listrik yang sesuai standar, pelatihan cara pemasangan dan perawatan panel surya. Diharapkan dengan adanya kegiatan PKM ini, ketergantungan listrik yang bersumber dari PLN akan berkurang, dan kesadaran petani akan pentingnya instalasi green haouse yang sesuai standar semakin meningkat, sehingga dapat menghemat biaya produksi dan meningkatkan jumlah pendapatan.
\end{abstract}

Kata kunci : Bunga Krisan, Panel Surya, Energi Alternatif, Green House.

\begin{abstract}
Patmasari I Farmers Group Blarang Village and Sekar Sari Farmers Group Gendro Village, Tutur District, Pasuruan Regency, is a farmer group engaged in the cultivation of chrysanthemum flowers. Chrysanthemum varieties are produced in a variety of ways and are sent to meet local market demands, namely Malang and Surabaya. The quality of flowers influences the selling price of chrysanthemum. The case in the field shows that the chrysanthemum flowers cultivated by farmers are still not good, one of the causes is the process of lighting additional chrysanthemum plants at night which are less than optimal still relying on electricity from PLN. At certain times there is often a power outage, especially during the rainy season. Besides that, the greenhouse electrical installations owned by farmers are still not standard, this will directly have an impact on the safety and quality of chrysanthemum production. The results of the activities that have been carried out are the assembly and installation of each 1,200 Watt PLTS that is used to supply electric power for lighting chrysanthemum plants on Mitra-1 and irrigation processes on Mitra-2. Revitalizing the electric house installation of greenhouse and nursery greenhouse. Besides that, counselling was also conducted on the utilisation of environmentally friendly alternative energy sources and electrical installations that were following the standards, training on how to install and maintain solar panels. It is expected that with this PKM activity, the dependence of electricity sourced from PLN will be reduced, and farmers' awareness of the importance of greenhouse installations that are in line with standards is increasing, so they can save production costs and increase the amount of income.
\end{abstract}

Keywords: Chrysanthemum Flowers, Solar Panels, Alternative Energy, Green House. 


\section{PENDAHULUAN}

Krisan dengan nama latin Chrysanthemum atau dikenal dengan bunga Seruni merupakan jenis tanaman yang berasal dari negara subtropis yang memiliki panjang hari siang lebih dari 12jam (Syafriyudin dan Ledhe, 2015). Walaupun demikian Krisan dapat dibudidayakan di negara tropis (Indonesia) yang memiliki panjang hari siang rata-rata kurang dari 12 jam, yakni dengan cara memodifikasi panjang hari siang selama 2-4 jam melalui penambahan cahaya lampu pijar 75-100 watt atau lampu essensial 18-23watt (Wiguna et al, 2015). Penambahan cahaya lampu dimaksudkan agar tidak terjadi inisiasi (fase generatif) lebih awal sebelum mencapai pertumbuhan vegetatif yang diinginkan. Pemberian cahaya tambahan dari lampu listrik terbaik dilakukan pada pukul 22.00 sampai dengan 02.00 (Ermawati et al, 2011).

Krisan merupakan salah satu jenis tanaman hias yang sangat populer dan memiliki nilai ekonomi yang relatif tinggi serta potensial untuk dikembangkan secara komersial (Mufarrikha et al, 2014). Bunga krisan banyak disukai masyarakat disamping memiliki keindahan karena keseragaman bentuk dan warna, juga karena memilliki kesegaran yang relatif lama, mudah dirangkai, waktu pembungaan dan panennya dapat diatur sesuai dengan keinginan. (Sukesi, 2010). Selain menghasilkan bunga potong dan tanaman hias dalam pot, beberapa varietas krisan juga dapat digunakan untuk mengobati batuk, nyeri perut, sinusitis, dans esak napas (Widiastuti et al, 2004).

Lokasi sentra pengembangan bunga krisan di Kabupaten Pasuruan berada di Kecamatan Tutur. Kecamatan Tutur terletak di dataran tinggi sebelah barat pegunungan Tengger dengan ketinggian antara 1.400 sampai dengan 1.600 meter di atas permukaan laut (dpl). Karena letak geografis di pegunungan, maka derah ini beriklim sejuk dengan suhu rata-rata 16 - 25 derajat celcius dan curah hujan 3.650 milimeter per tahun. Kecamatan Tutur memiliki luas wilayah $94 \mathrm{~km} 2$ dan terbagi menjadi dua kelompok, yaitu: (1) desa berkembang yang terdiri dari Desa Wonosari, Gendro, Tlogosari, Blarang, Andono Sari, Kayu Kebek, Ungging, Tutur, Sumberpitu, dan Kali Pucang; dan desa pengembangan, terdiri dari: Desa Ngembal dan Ngadirejo (dikutip dari repository IPB Bogor).

Budidaya bunga krisan di Kecamatan Tutur dilakukan oleh petani yang tergabung dalam Koperasi Agro Mitra yang didirikan pada tahun 2004 yang beranggotakan 80 petani. Dari 12 Desa yang berada di wilayah Kecamatan Tutur baru 7 desa yang tergabung dalam 4 kelompok petani (KP) yang menjadi pusat budidaya bunga krisan, yaitu KP Sekar Sari yang berada Desa Gendro, KP Sekar Alam yang berada desa Tutur, KP Patmasari I yang berada Desa Blarang dan KP Patmasari II yang berada di Desa Wonosari.

Salah satu petani bunga krisan yang tergabung dalam KP PatmasariI Bapak M. Yahya Sucipto atau yang akrab dipangil Pak Cip, memiliki lahan budi m2ya bunga krisan seluas \pm $4.000 \mathrm{~m} 2$ dengan 3 jenis green house, yaitu green house induk-an, green house pembibitan dan green house produksi. Pada awal memulai usaha budidaya krisan, bibit didatangkan/ dibeli dari petani krisan yang berada di luar Kabupaten Pasuruan dengan harga per bibit Rp. 250 ,-. Dengan bertambahnya pengetahuan mengenai budidaya krisan dan sebagai upaya untuk mengurangi biaya produksi, maka dibangunlah green haouse indukan dan green house pembibitan sendiri sampai sekarang. Greenhouse indukan dan pembibitan yang dimiliki seluas $\pm 500 \mathrm{~m}^{2}$ dan sisanya yaitu $\pm 3.500 \mathrm{~m}^{2}$ merupakan green house produksi. Kebutuhan pencahayaan untuk green house pembibitan dan indukan berbeda dengan kebutuhan pencahayaan untuk green house produksi. Green house produksi membutuhan pencahayaan tambahan pada malam hari selama kurun waktu 2-4 jam perhari selama ( \pm 1 bulan), setelah fase vegetatifnya terpenuhi maka pencahayaan tambahan tidak diperlukan lagi sedangkan green house indukan dan pembibitan membutuhkan pencahayaan sepanjang waktu.

Petani bunga krisan lainnya yang tergabung dalam KP Sekar Sari Bapak Rudi Kurniawan, memulai usaha budidaya bunga krisan sejak tahun 2002 dengan lahan seluas $2.000 \mathrm{~m}^{2}$ (green house produksi). Hanya mampu menghasilkan 500 bungkus per minggu, bunga krisan yang dihasilkan dikirim ke wilayah Surabaya dan Malang. 
Menurut penuturan Pak Yahya dan Pak Rudi, untuk memenuhi permintaan pasar lokal Surabaya dan Malang masih sangat kurang, karena hanya mampu mengirim 700 - 800 ikat bunga krisan atau 7.000-8.000 tangkai bunga krisan per minggu dengan harga pertangkai Rp. $1.200,-$ (Kelas A). Hal ini disebabkan karena kualitas produksi yang masih rendah dan penerapan teknologi budidaya yang belum standar sesuai dengan yang tertuang pada standar operasi prosedur (SOP) bunga krisan. Disamping itu, pasokan listrik dari PLN yang masih kurang kontinyu karena sering terjadi pemadaman listrik, terlebih pada musim hujan. Sehingga bagi petani seperti Pak Yahya dan Pak Rudi yang tidak memiliki peralatan backup daya listrik (Genset) untuk pencahayaan greenhouse pada malam hari tentunya sangat merugikan. Disamping itu, kondisi instalasi listrik greenhouse yang masih kurang standar, hal itu terlihat dari penggunaan kabel yang tidak sesuai peruntukannya, tidak menggunakan pengaman, sambungan kabel yang tidak menggunakan isolasi, tidak menggunakan reflektor lampu, jarak antara titik lampu tidak standar, ketinggian titik lampu dengan permukaan bunga krisan yang tidak standar dan pemakaian satu saklar untuk melayani 39 titik lampu. Dimana hal sangat sangat membahayakan karena dapat menimbulkan rugi-rugi baik itu tagihan listrik yang meningkat, pencahayaan yang tidak optimal yang akan berdampak langsung pada proses pertumbuhan (fase vegetative dan generatif) bunga krisan dan bahaya kebakaran yang ditimbulkan akibat tidak terpenuhinya pemasangan instalasi yang sesuai dengan standar.

Faktor pendukung keberhasilan budidaya bunga krisan disamping instalasi listrik atau penerangan green house yang sesuai standar juga penyediaan energi listrik yang kontinyu untuk pencahayaan dimalam hari, dan menggerakan pompa untuk keperluan irigasi/penyiraman di siang hari baik untuk green house indukan, pembibitan dan produksi. Penyediaan energi listrik dikembangkan dengan menggunakan energi alternatif yang ramah lingkungan, terbarukan, yaitu dengan penerapan teknologi panel surya dengan memanfaatan energi matahari. Keuntungan penggunaan energi matahari adalah sebagai sumber energi ramah lingkungan, berlimpah, terbarukan, dan dapat digunakan secara langsung maupun tidak langsung (Jalaluddin et al, 2015; Ermawati, et al., 2011; Mufarrikha, et al., 2014; Sukesi, 2010; Wiguna, et al ., 2015).

Permasalahan umum usaha budidaya bunga krisan ini yaitu penyediaan energi listrik yang masih tergantung dari PLN baik untuk keperluan penerangan dan irigasi serta kurangnya kesadaran petani bunga krisan akan pentingnya instalasi listrik green house yang aman sesuai dengan standar.

\section{METODE}

Pelaksanaan kegiatan PKM Kelompok Petani Bunga Krisan di Desa Blarang dan Desa Gendro Kabupaten Pasuruan, dapat dibagi menjadi beberapa tahapan sebagai berikut.

\section{Persiapan}

a. Melakukan kunjungan ke lokasi mitra, yaitu kelompok petani Patmasari I dan Sekar Sari. Tujuannya untuk mendapatkan informasi sebanyak mungkin mengenai permasalahan yang dihadapi mitra. Melihat langsung proses budidaya tanaman krisan, instalasi listrik green house anggota kelompok petani bungakrisan.

b. Melakukan wawancara, tujuannya untuk mendapatkan informasi mengenai profil kelompok tani, anggota yang aktif, hasil budidaya, kemampuan produksi, penjualan dan keuntungan yang diperoleh setiap bulannya.

c. Melakukan pengumpulan data, meliputi perhitungan jumlah titik lampu untuk penerangan green house, pengukuran besarnya daya yang dipakai, pengukuran intensitas cahaya, pengecekan rugi-rugi (faktordaya, harmonisa, nilai arus), pengecekan kabel, pengecekan peralatan pengaman. 
d. Setelah informasi dan data diperoleh secara lengkap, selanjutnya melakukan perencanaan peralatan dan komponen-komponen yang akandigunakan.

\section{Pelaksanaan Kegiatan}

a. Pengadaan alat sebagai sumber energi alternatif, berdasarkan hasil diskusi dengan mitra diprioritaskan berupa panel surya beserta komponen-komponen pendukunglainnya.

b. Melakukan revitalisasi instalasi listrik green house, meliputi pergantian kabel, penambahan reflektor lampu, mengatur ulang jarak antar lampu, ketingian lampu dengan permukaan tanah.

c. Melakukan penyuluhan mengenai manfaat energi surya sebagai sumber energi listrik alternatif dan pentingnya instalasi listrik green house yang sesuai standar. Mengadakan pelatihan pemasangan dan perawatan panel surya.

\section{Peran Mitra}

Peran mitra yaitu menyiapkan tempat dan memobilisasi anggota kelompok untuk hadir pada kegiatan ini. Selanjutnya anggota kelompok petani yang sudah terlatih ini, kedepannya akan memberikan penyuluhan dan pelatihan kepada kelompok petani lainnya yang berada di wilayah Kecamatan Tutur Kabupaten Pasuruan.

\section{HASIL DAN PEMBAHASAN}

\section{Perakitan dan Pemasangan Peralatan PLTS}

Adanya kegiatan program kemitraan masyarakat (PKM) ini memberikan dampak positif bagi petani bunga krisan, yaitu memberikan solusi terkait dengan permasalahan yang dihadapi petani bunga krisan yaitu penyediaan sumber energi alternatif dari panel surya. Kegiatan (PKM) ini diawali dengan koordinasi dengan TIM yang dilaksanakan pada hari senin tanggal 19 maret 2018 yang bertempat Program Studi Teknik Listrik DIII ITN Malang. Selanjutnya melakukan koordinasi dengan Mitra 1 dan Mitra 2 pada hari rabu tanggal 25 Juli 2018. Kegiatan pertama yang dilakukan yaitu perakitan dan uji coba peralatan yang dilakukan di Workshop Teknik Listrik DIII ITN Malang. Spesifikasi peralatan yang digunakan untuk kegiatan PKM ini yaitu:

a. Pembangkit Tenaga Surya (PLTS) untuk penerangan dan irigasi:

$$
\begin{aligned}
& \text { - Panel Surya Mono Crystallin : } 8 \text { unit, } 100 \mathrm{Wp} \\
& \text { - Solar Charger Control MPPT : } 2 \text { unit, 40A } \\
& \text { - Inverter Pure Sine Wave } \quad: 2 \text { unit, } 1.200 \mathrm{Wa} \\
& \text { - Baterai Kering VRLA : :4 unit, 100Ah } \\
& \text { - Kabel NYAF1,5 } \mathrm{mm}^{2} \quad: 1 \text { roll, 50meter } \\
& \text { - Konektor MC4 :8 pcs }
\end{aligned}
$$

b. Revitalisasi instalasi greenhouse:

- Reflektor \& fitting lampu Ø $30 \mathrm{~cm}$ : 45 unit

- Kabel NYA 1,5 $\mathrm{mm}^{2} \quad: 10$ rol, 100 meter

- Luxmeter : : 1 unit

- Isolasi bakar $\quad: 10$ meter

c. Panel control otomatis

$$
\begin{aligned}
& \text { - MCB6 Amper : : } 4 \text { unit } \\
& \text { - MCB4 Amper : :2 unit } \\
& \text { - Relay 220 V } 10 \text { A+ Soket: } 6 \text { unit } \\
& \text { - Relay } 12 \text { Volt + soket : } 2 \text { unit } \\
& \text { - Pilotlamp :4 unit } \\
& \text { - Voltmeter dan ampermeter: } 4 \text { unit } \\
& \text { - Saklar SPDT : : } 1 \text { unit }
\end{aligned}
$$


Perakitan (PLTS) yang dilakukan masing-masing 4 panel surya yang dipasang paralel dan 2 batrei Valve Regulated Lead Acid (VRLA) yang dihubungkan secara paralel, baik untuk penerangan dan irigasi. Uji coba dilakukan dengan memberikan beban berupa, beban blower 150 Watt dan beban grinda sebesar 450 Watt, dan hasilnya kedua jenis beban tersebut dapat bekerja dengan baik. Untuk memudahkan pengoperasian PLTS dan PLN maka dibuatkan juga sistem switch otomatis (ATS) yang digunakan untuk mematikan dan menghidupkan lampu secara otomatis mulai pukul 18.00 WIB sampai dengan pukul 21.00 WIB selama 3 jam pada mitra-1, disamping itu dengan adanya ATS ini jika PLTS tidak mampu mensuplai listrik akibat tidak adanya matahari maka sacara otomatis suplai penerangan akan diambil alih oleh sumber listrik dari PLN. Gambar 1 sampai 4 memperlihatkan proses perakitan panel surya dan panel kontrol otomatis (ATS).

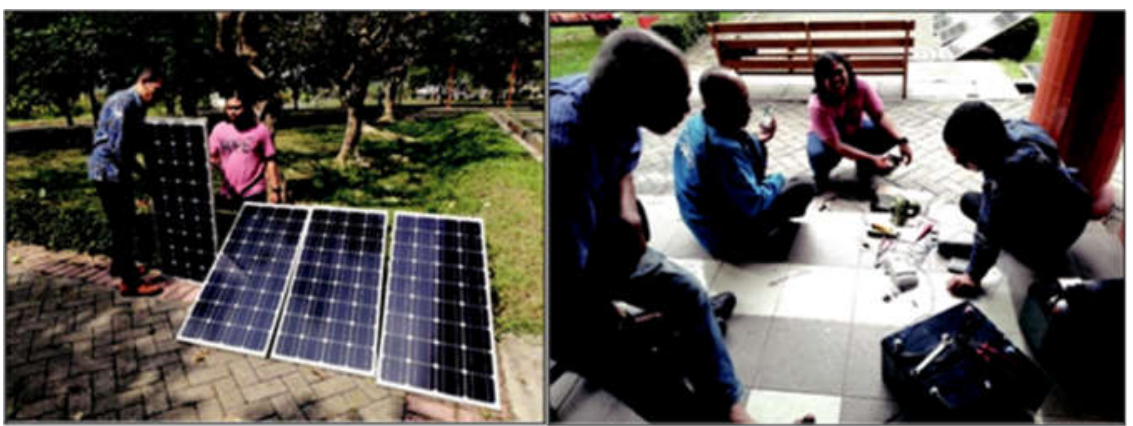

Gambar 1. Perakitan dan Uji coba PLTS di Workshop Teknik Listrik D-3 ITN Malang.
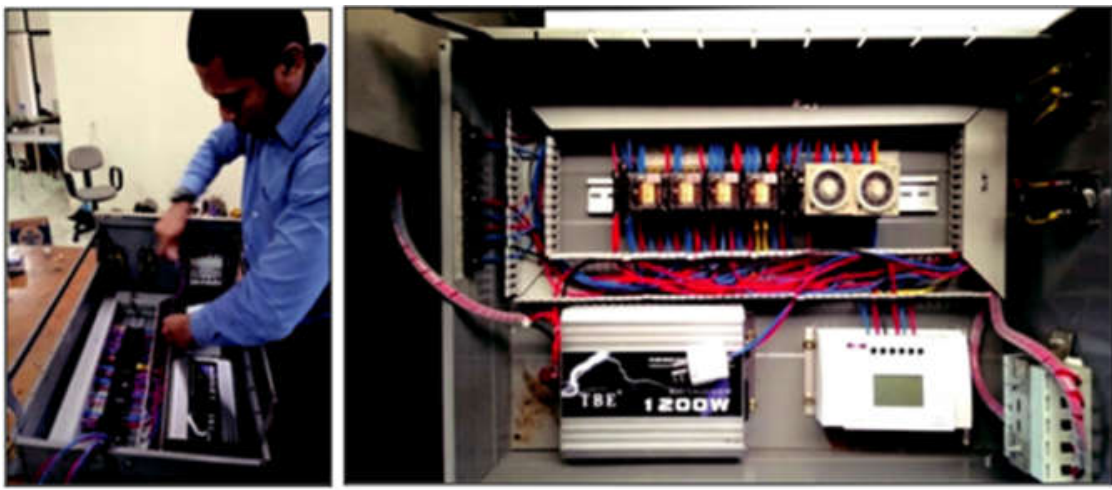

Gambar 2. Perakitan panel kontrol otomatis (ATS)

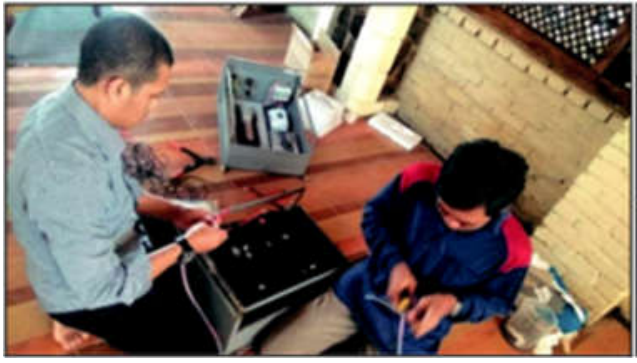

(a)

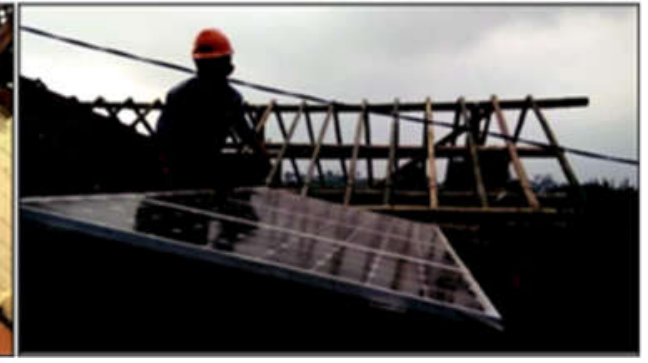

(b)

Gambar 3. (a) Pemasangan batrei (b) pemasangan panel surya di lokasi mitra 


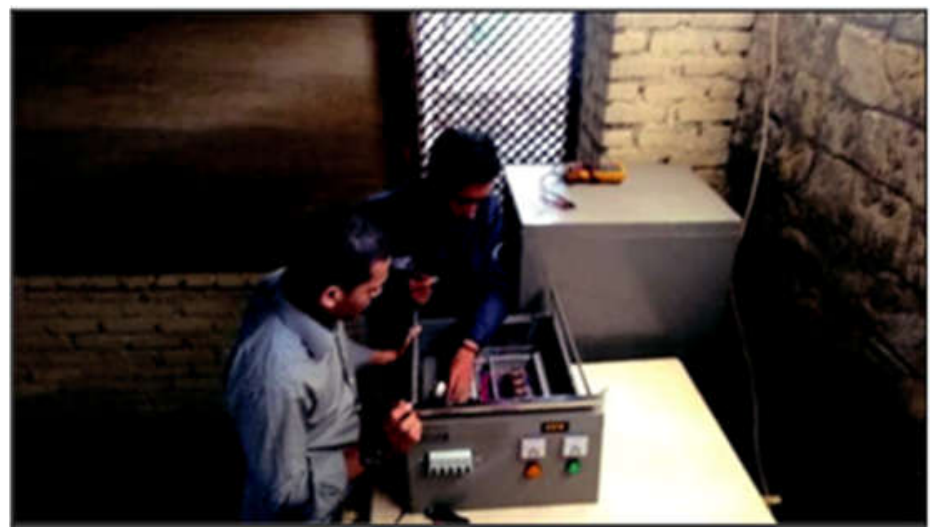

Gambar 4. pemasangan panel kontrol otomatis (ATS) di lokasi mitra

Kegiatan kedua yaitu melakukan pemasangan PLTS di kedua mitra. Pemasangan di mitra-1 difokuskan untuk penerangan green house indukan dan pembibitan bunga krisan total beban yang akan disuplai sebesar $620 \mathrm{Watt}$, dengan 45 titik lampu. Pemasangan di mitra-2 difokuskan untuk irigasi/pompa.

\section{Kondisi green house setelah direvitalisasi}

Gambar 5 memperlihatkan kondisi green house sebelum dilakukan revitalisasi, dimana banyak kabel yang bertegangan dibiarkan terbuka (tanpa isolasi), sambungan kabel yang tidak dilengkapi dengan isolasi yang tentunya sangat membahayakan petani pada saat berkegiatan. Disamping itu lampu yang tidak menggunakan reflektor dapat menyebabkan pencahayaan tidak merata yang dapat mempercepat fase inisiasi lebih awal sebelum tercapai fase vegetatif yang diinginkan.

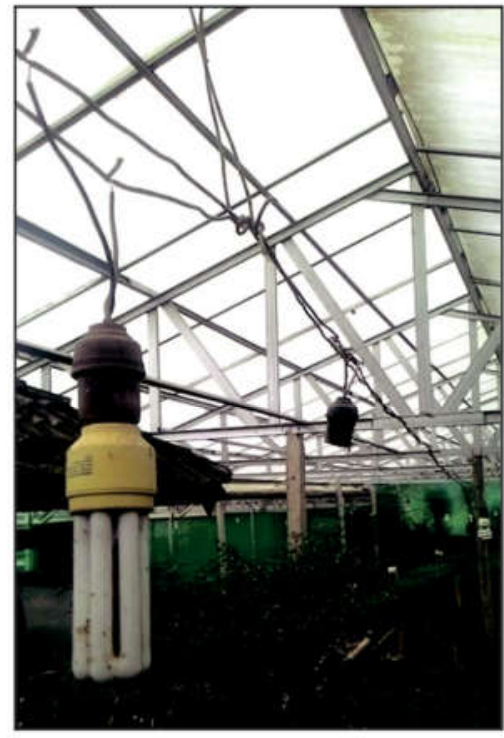

(a)

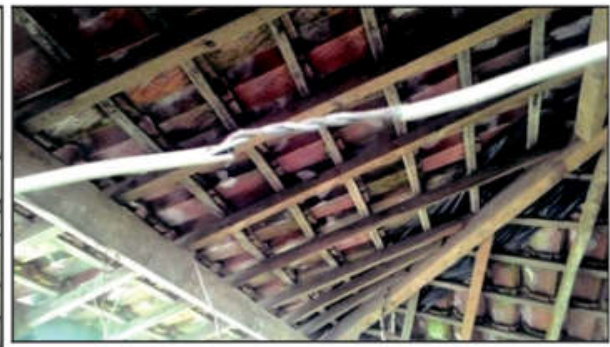

(b)

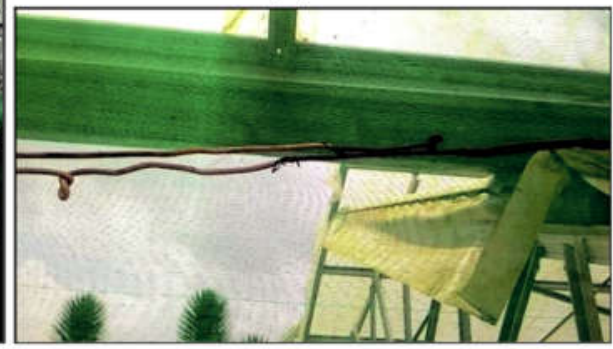

(c)

Gambar 5. (a) Lampu tanpa reflektor (b) kabel bertegangan dibiarkan terbuka (c) sambungan kabel yang dibiarkan terbuka tanpa isolasi. 
Gambar 6 memperlihatkan kondisi green house yang telah dilakukan revitalisasi dengan menambahkan reflektor lampu dengan diamter $30 \mathrm{~cm}$, ini bertujuan agar pencahayaan yang dipancarkan bisa fokus tertuju kepada tanaman krisan sehingga fase insisiasinya tidak cepat terjadi sebelum fase vegetatif tercapai. Penggunaan kabel yang sebelumnya tidak standar (diameter $0,75 \mathrm{~mm}^{2}$, tidak berisolasi) sekarang sudah diganti dengan kabel standar (diameter $1,5 \mathrm{~mm}^{2}$, berisolasi) yang dilengkapi dengan kabel spiral agar wiring-nya lebih rapi seperti yang terlihat pada Gambar 7. Berdasarkan hasil pengukuran dengan menggunakan alat ukur tegangan, nilai tegangan ujung beban lampu green house sebelum direvitalisasi sebesar $\mathrm{V}=120,5$ Volt setelah dilakukan revitalisasi nilai tegangan naik menjadi $\mathrm{V}=227,2$ Volt seperti yang terlihat pada Gambar 8 .
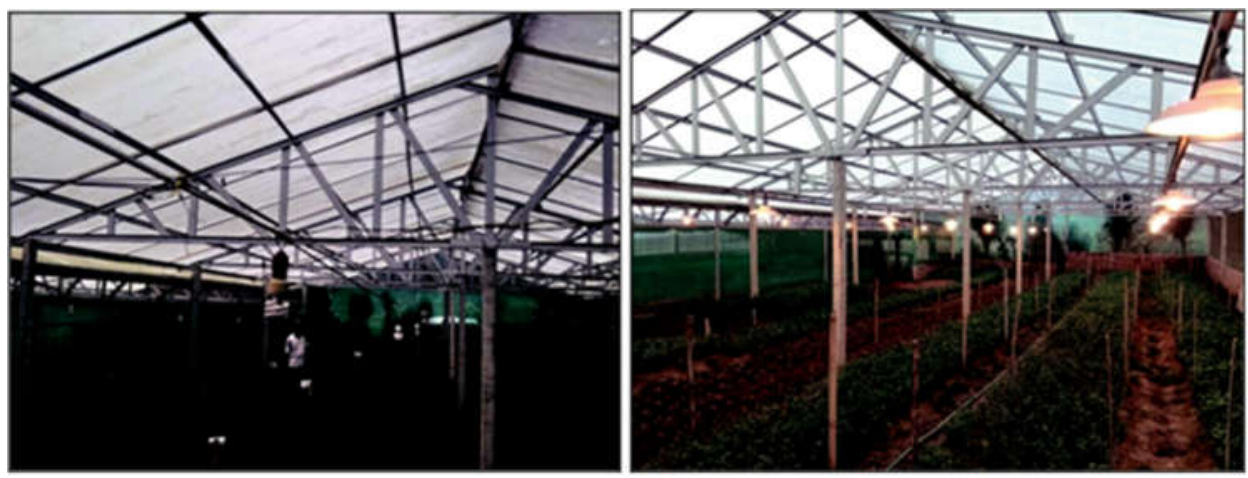

Gambar 6. Kondisi green house sebelum direvitalisasi (kiri) dan sesudah direvitalisasi (kanan)
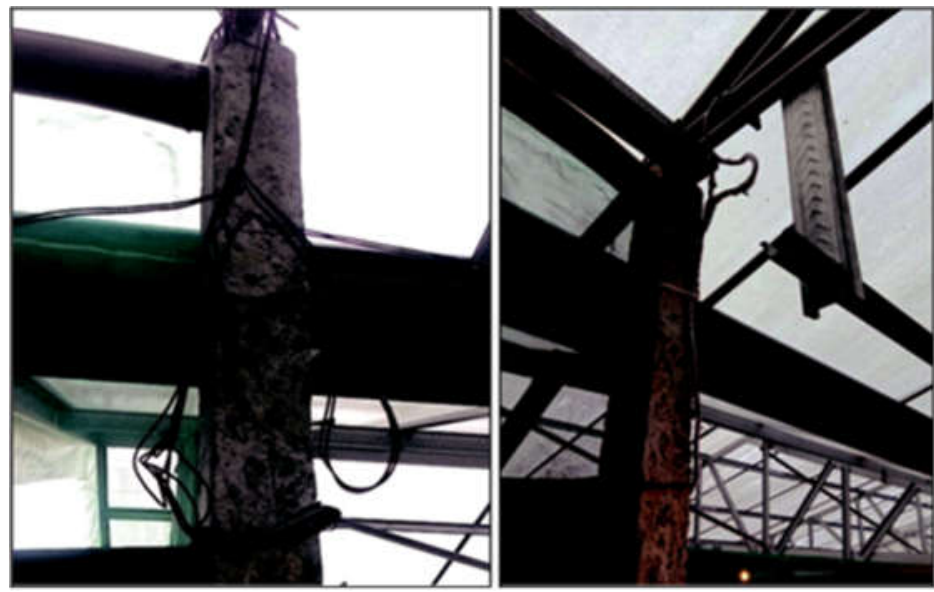

Gambar 7. Kondisi kabel sambungan dan percabangan tanpa isolasi (kiri) dan sesudah direvitalisasi (kanan)
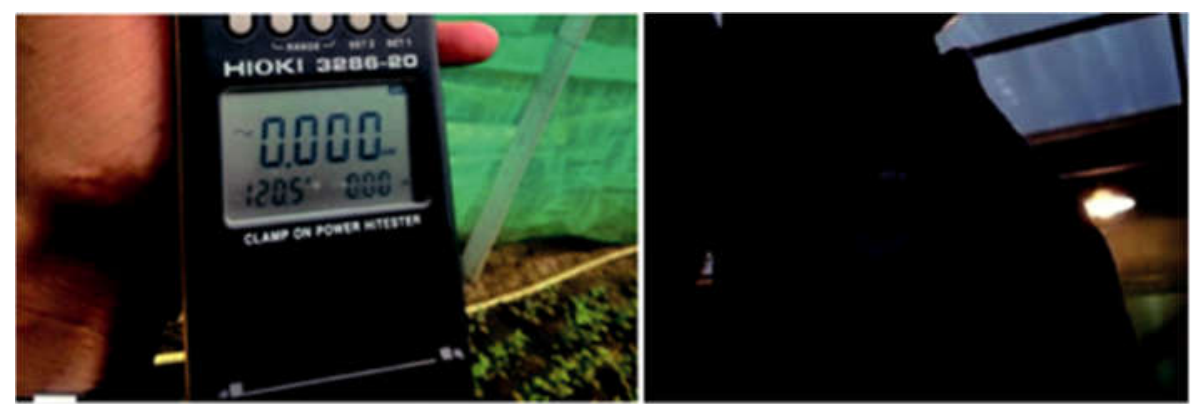

Gambar 8. Nilai tegangan sebelum (kiri) dan sesudah direvitalisasi (kanan) 


\section{DAMPAK DAN MANFAAT}

Bunga krisan hasil budidaya para petani masih kurang baik hasilnya, salah satu penyebabnya yaitu proses pencahayaan tambahan tanaman krisan di malam hari yang kurang maksimal masih mengandalkan sumber energi listrik dari PLN. Dengan pemasangan masingmasing PLTS kapasitas 1.200 Watt yang digunakan untuk suplai daya listrik untuk pencahayaan tanaman krisan pada Mitra-1. Sehingga pada saat-saat tertentu, sering terjadi pemadaman listrik terlebih pada saat musim hujan dan instalasi listrik green house yang dimiliki petani masih belum standar, hal ini secara langsung akan berdampak pada keamanan dan kualitas hasil produksi bunga krisan. Dengan pemanfaatan sumber energi alternatif yang ramah lingkungan dan instalasi listrik yang sesuai standard dan pemasangan panel surya maka ketergantungan listrik yang bersumber dari PLN akan berkurang, dan kesadaran petani akan pentingnya instalasi green haouse yang sesuai standar semakin meningkat, sehingga dapat menghemat biaya produksi dan meningkatkan jumlah pendapatan.

\section{KESIMPULAN}

Kegiatan Program Kemitraan Masyarakat yang dilakukan di Desa Blarang dan Desa Gendro berupa penerapan teknologi Panel Surya untuk petani Bunga krisan dapat terlaksana dengan baik. Penyediaan tenaga listrik dari energy matahari dapat membantu petani dalam meningkatkan proses budidaya bunga krisan karena energi listrik akan terus tersedia. Disamping itu dengan adanya sistem otomatisasi petani tidak perlu khawatir jika green house ditinggal, karena lampu green house akan menyala dan padam secara otomatis sesuai dengan waktu yang sudah diatur. Setelah dilakukan revitalisasi green house rugi-rugi daya dan tegangan dapat diminimalisir.

\section{UCAPAN TERIMA KASIH}

Terima kasih disampaikan kepada Direktorat Riset dan Pengabdian Masyarakat Kementerian Riset, Teknologi dan Pendidikan Tinggi yang tel ah membiayai kegiatan Pengabdian Masyarakat Tahun Anggaran 2018.

\section{REFERENSI}

Ermawati, D., Indradewa, D. dan Trisnowati, S. (2011) 'Pengaruh Warna Cahaya Tambahan Terhadap Pertumbuhan dan Pembungaan Tiga Varietas Tanaman Krisan (Chrysanthemum Morifolium) Potong', Fakultas Pertanian Universitas Gadjah Mada. Yogyakarta.

Jalaludin., Jalil, R. A., Tarakka, R. dan Wardi. (2015) 'Pemberdayaan Masyarakat dengan Pemanfaatan Sumber energi Terbarukan pada Tambak Udang', Jurnal Ilmiah Pengabdian kepada Masyarakat, 1(2), 136-141.

Mufarrikha, L., Herlina, N. dan Widaryanto, E. (2014) 'Respon Kultivar Tanaman krisan (Chrysanthemum Morifolium) pada Berbagai Lama Penambahan Cahaya Buatan', Jurnal Produksi Tanaman, 2(1), $10-16$.

Sukesi (2010) 'Perencanaan Usaha Teknik Membuat Kelayakan Usaha dilengkapai Contoh Beberapa Model Usaha Agribisnis', Lutfansah Mediatama. Surabaya.

Syafriyudin dan Ledhe, T. (2015) 'Analisis Pertumbuhan Tanaman Krisan pada Variabel Warna Cahaya Lampu LED’, Jurnal Teknologi, 8(1), 83-87.

Widiastuti, L., Tohari., dan Sulistyaningsih, E. (2004) 'Pengaruh Intesitas Cahaya dan Kada Daminosida Terhadap Iklim Mikro dan Pertumbuhan Tanaman Krisan dalam Pot', Jurnal Ilmu Pertanian, 11(2), 35-42.

Wiguna, W. I K., Wijaya, A, I M., dan Nada, I M. (2015) 'Pertumbuhan Tanaman krisan (Crhysantemum) dengan berbagai Penambahan Warna caha Lampu LED Selama 30 Hari 
pada Fase Vegetatif', Program Studi Teknik Pertanian, Fakultas Teknologi Pertanian, Universitas Udayana.

http://repository.ipb.ac.id/jspui/bitstream/123456789/41024/8/Bab\%205\%20\%202008kmu.pdf diakses pada hari Rabu 26 April 2017 Jam 22.00 WIB. 